\title{
EVALUATING MOBILE LASER SCANNING FOR LANDSLIDE MONITORING
}

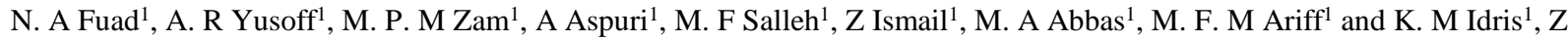 \\ Majid $^{1 *}$ \\ ${ }^{1}$ Geospatial Imaging and Information Research Group, Faculty of Geoinformation and Real Estate, Universiti Teknologi Malaysia - \\ (syasya3093, ahmadrazali89, azwanabbas, en.pojie)@gmail.com, (anuaraspuri, mohdfaizi, zamriismail, mfaridma, khairulnizami, \\ zulkeplimajid)@utm.my
}

Commission VI, WG VI/4

KEY WORDS: Mobile Laser Scanning, Landslide, Mapping, Monitoring, Accuracy

\begin{abstract}
:
Landslide is one of the natural disasters that give a huge impact to human life and social-economic development. Landslide needs to be monitored periodically in order to avoid loss of human life and damages of properties. Various methods have been used for monitoring landslide. This aim of the research is to evaluate the potential of mobile laser scanning technique for monitoring of landslide area. The objectives of the research are to acquire three-dimensional surface data of landslide area in different epochs and to analyze the movement of the landslide area using three-dimensional surface deviation and ground surveying techniques. The methodology begins with the GPS survey for the establishment of ground control points for the project area. The total station survey was then carried out to measure the three-dimensional coordinates of twenty well distributed targets located at the project area. The data collection phase was then continuing with the mobile laser scanning survey. The processing of the two epochs data acquired from both techniques was then carried out simultaneously and the methodology concluded with the output comparison analysis for the movement detection of the land slip. The finding shows that the mobile laser scanning provides fast and accurate data acquisition technique of the landslide surface. The surface deviation analysis of the two epochs laser scanning data was capable to detect the movement occurred in the project area. The results were successfully evaluated using the changes of the threedimensional coordinates of the targets from the two epoch's ground surveying data.
\end{abstract}

\section{INTRODUCTION}

Landslide is one of the natural disaster that give a huge impact on the population and socio-economic in Malaysia. The government and private sector are forced to withstand the losses and damage caused by landslide either in direct or indirect ways. In fact, the landslide incident can also lead to death if landslide occurred at large scale of housing and road area. Malaysia experienced a kind of equatorial climate in which it described the climate is hot and humid all year round. Landslides often occur in the country during the rainy season due to high rainfall rates of up to $2000 \mathrm{~mm}$ to $3000 \mathrm{~mm}$ per year. With the increasing of current economic magnitude, there is a need to find the best and fastest ways to monitor landslide. Issues regarding to landslide can be solved in rapid ways due to many professional and scientific fields has been influenced by the development of new technology which simplify their use and their endorsement of general population.

According to Babić et al., (2012) one of the most affected and no exclusion by this changing of technologies is geodesy. This is because the paradigm of geodesy has been changed extremely by the possibility of free access of satellite imagery, can publicly access databases, low-cost GPS devices and free connection to the site information such as Land Parcel Information Systems (LPIS). Besides, the transition of spatial information from 2D to 3D or even 4D by introducing the new laser scanning technologies in landslide study also give effects to the changes related to geodesy.
Light, Detection and Ranging (LiDAR) technology such as Terrestrial Laser Scanning (TLS) and Airborne Laser Scanning (ALS) were used in the monitoring of landslide phenomena. The latest technology that can be used to monitor landslide is Mobile Laser Scanning (MLS). MLS provides fast, accurate and very efficient in collecting landslide data. MLS is a technique where mobile platform been used to capture geospatial data. This become an extension between the gap of aerial and terrestrial laser scanning in terms of the level details of data captured (Kukko, 2013). MLS system can be mounted on any moving vehicle such as bicycles, cars, trolleys for railway, backpack and boats. It is very highly flexible in capturing spatial data while driving or crossing a route which promises on giving a highly accurate 3D data and can obtain an accurate sub-centimeter survey data that been geo-referenced. The data gained from MLS can be processed in the GIS software and various types of spatial analyses can be carried out for mapping and monitoring of landslide phenomena.

\section{LITERATURE REVIEW}

Light detection and Ranging (LiDAR) is a new technology for collecting three-dimensional surface data of an object. Nowadays, the LiDAR technology can be categories in three main categories which are airborne-based LiDAR, terrestrialbased LiDAR and mobile-based LiDAR. The mobile-based LiDAR or popularly known as Mobile Laser Scanning (MLS) becomes the latest LiDAR system where the three-dimensional point cloud of the object was collected from the moving laser scanner setup on the vehicle. Mobile laser scanning (MLS) starts with the stop-and-go scanning mode to collect the point 
cloud data. Nowadays, the innovation in the MLS system makes the system running of the on-the-fly mode. Not only that, the current MLS system can be carried by human for data collection at the un-access area. Figure 1 show the concept applied in MLS surveying.

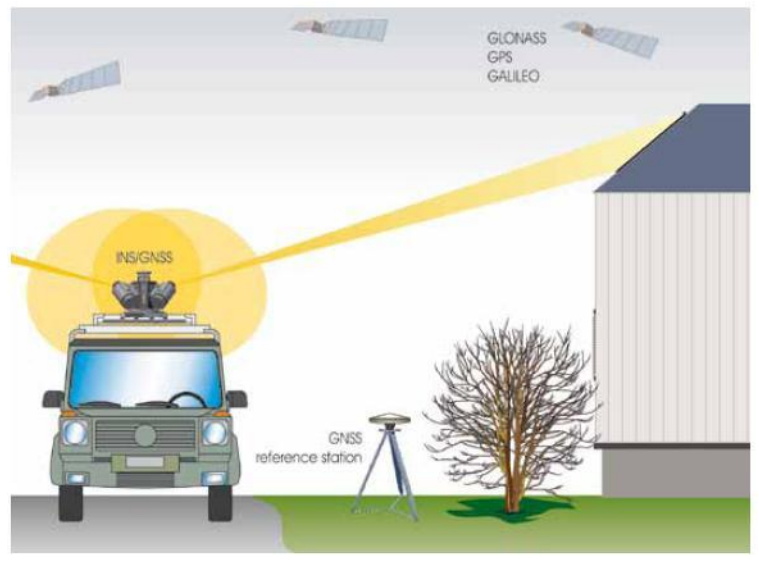

Figure 1. The concept of mobile laser scanning survey (Wang H et. al (2012))

Mobile laser scanning technology has been widely used in mapping and monitoring of landslide area. Michoud et al (2015) carried out a research to evaluate the capability of a boat-based mobile laser scanning system for landslide detection and monitoring at the Dieppe coastal cliffs, Normandy. The scanning process was performed at two different periods. The assessment involved the potential of the scanning system for 3D modeling, change detection and landslide monitoring tasks.

Vaaja et al (2011) implements mobile laser scanning technology for mapping of topographic changes and evaluate the elevation accuracies. The research evaluates the capability of mobile laser scanning system in erosion change mapping. The findings shows that the mobile laser scanning proved to be the best solution when a close viewpoint, dense point clouds, and high ranging accuracy was needed.

Xio et al (2015) used mobile laser scanning technology to detect the street environment changes. The advantage of mobile laser scanning system is it is easy to revisit the interested area due to the high mobility of the system. The research generates an innovative approach that combines occupancy grids and a distance-based method for change detection from mobile laser scanning point clouds data.

Qin and Gruen (2014) have carried out a research on 3D change detection at street level using mobile laser scanning point clouds and terrestrial images. The research has found out that the mobile laser scanning data that have been acquired from different epochs provides accurate 3D geometry for change detection analysis. The research involves with the development of a new method for change detection at street level by combining mobile laser scanning point clouds and terrestrial images.

According to Wang $\mathrm{H}$ et. al (2012), mobile laser scanning technology as a new information acquiring manner can quickly scan the whole scene and provide density and accurate 3D coordinate data and other information. In the research, the road extraction process was carried out based on trajectory information that was gathered from mobile laser scanning data.
The location and approximate direction of the road was determined from the trajectory. This research also proposed a new algorithm for automatic road surface and boundary extraction from point cloud dataset.

\section{METHODOLOGY}

The methodology of the research involves with four phases. The phases are:

a) Setup of measurement targets

b) Data collection

c) Data processing, and

d) Data analysis

The complete explanations of each phase are as follows.

\subsection{Phase 1 - Setup of Measurement Targets}

The first phase involves with the setup of measurement targets at the landslide are. In this research, the black and white paper targets with an individual sign were used. The location of the measurement targets is well distributed. Figure 2 shows the landslide area with the measurement targets.

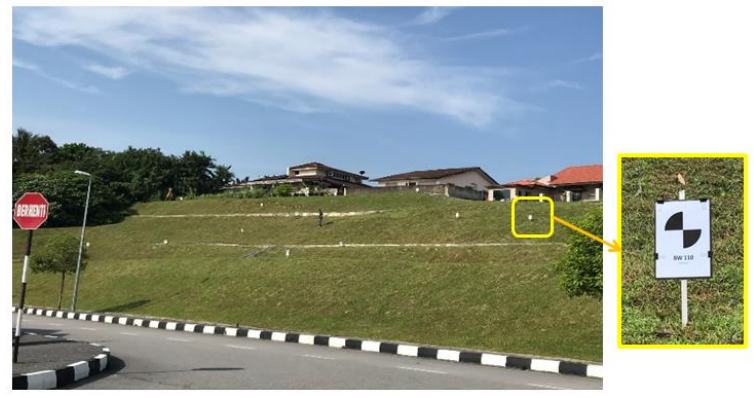

Figure 2. The landslide area with the well-distributed measurement targets

Figure 3 below shows the images of landslide and building cracks that occurred at the study area.

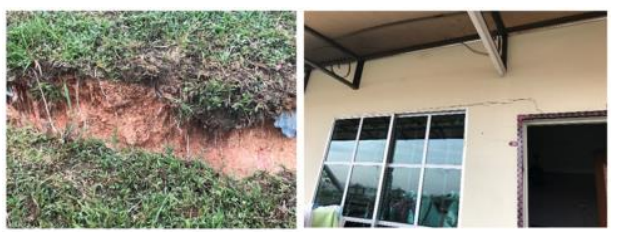

Figure 3. Images of landslide and building cracks at the study area

\subsection{Phase 2 - Data Collection}

Three types data collection involved in the research. The first data collection involves with the GPS control survey. Four ground control points was established at the landslide area. Figure 4 shows the GPS control survey equipment used in the research. While Figure 5 shows the location of four GPS control points at the study area. 


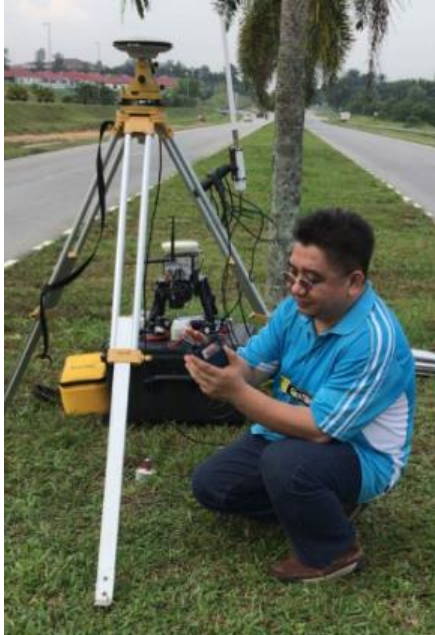

Figure 4. GPS control survey

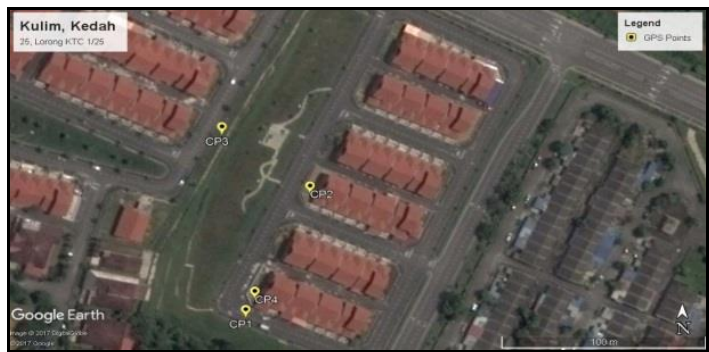

Figure 5. The location of four GPS control points at the study area

The second data collection involves with the total station survey of the measurement targets. The survey was carried out from two known surveying stations. Figure 6 shows the researcher with the total station equipment. The vertical angles, horizontal angles and the distances between the surveying stations and the measurement targets were observed at the survey grade accuracy. Figure 7 shows the surveying intersection concept applied in the research.

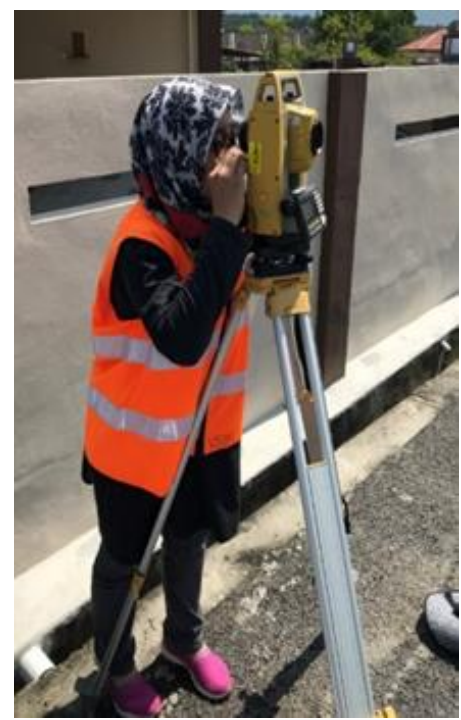

Figure 6. Total station survey

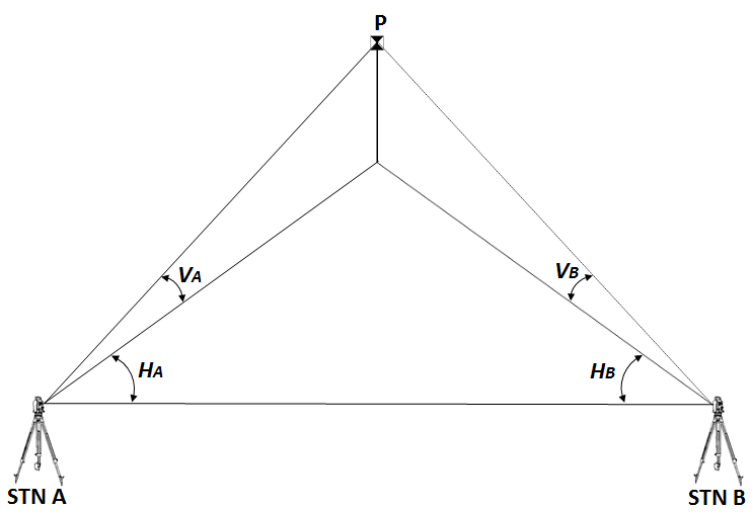

Figure 7. Surveying intersection concept - where P, HA and $\mathrm{HB}$, and VA and VB are the measurement target, horizontal angles and vertical angles, respectively

The third data collection involves with the mobile laser scanning survey. The mobile laser scanning was carried out in two modes which are on-the-fly mode (vehicle-based) and human-based mode. The human-based scanning was carried out at the un-covered scanning area. Figure 8 shows the data collection using mobile laser scanning equipment.

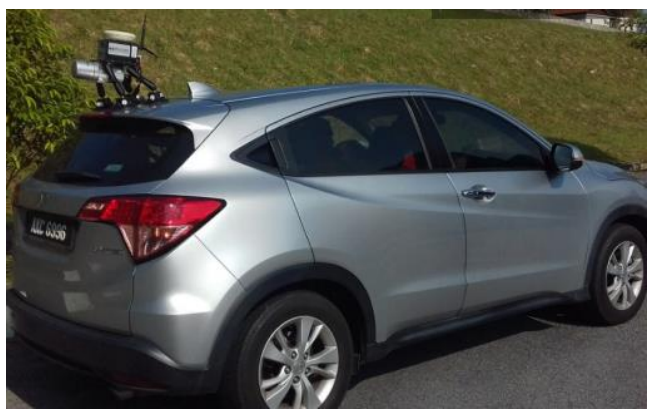

Figure 8. Data collection with mobile laser scanning equipment

The mobile laser scanning survey was carried out using a customized version of an airborne Phoenix AL3 system (as shown in Figure 9). The system was equipped with the specialbuilt vehicle mounting device. The mounting device allows the system to be setup at any type of vehicle to perform a mobilemode scanning process.

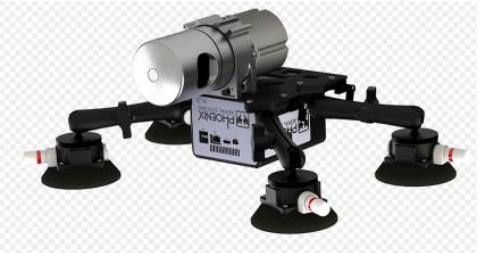

Figure 9. The Phoenix AL3 mobile laser scanning system

Table 1 shows the brief specifications of the Phoenix AL3 system. 


\begin{tabular}{|l|l|}
\hline \multicolumn{2}{|c|}{ Phoenix AL3 System } \\
\hline Absolute Accuracy & $\begin{array}{l}\text { 25 / 35mm RMSE @ 50m } \\
\text { Range }\end{array}$ \\
\hline Weight & $3.2 \mathrm{~kg} / 7 \mathrm{lb}$ \\
\hline Laser Range & $107 \mathrm{~m}$ \\
\hline Scan Rate & $700 \mathrm{k}$ shots/s, up to 2 returns \\
\hline
\end{tabular}

Table 1. Brief specifications of Phoenix AL3 System

Both total station and mobile laser scanning surveys was carried out in two epochs within 30 days period.

\subsection{Phase 3 - Data Processing}

The data processing phase begins with processing of GPS data to calculate the GPS local coordinates based on the absolute reference stations. Table 2 shows the GPS coordinates of the four control points.

\begin{tabular}{|c|c|c|c|}
\hline Points & Latitude & Longitude & Height (m) \\
\hline BABH & $5^{\circ} 08^{\prime} 47.97274^{\prime \prime} \mathrm{N}$ & $100^{\circ} 29^{\prime} 37.17651^{\prime \prime} \mathrm{E}$ & 9.011 \\
\hline BAYO & $5^{\circ} 15^{\prime} 04.81608^{\prime \prime} \mathrm{N}$ & $100^{\circ} 45^{\prime} 20.63767^{\prime \prime} \mathrm{E}$ & 20.879 \\
\hline $\mathrm{CP} 1$ & $5^{\circ} 23^{\prime} 39.64000^{\prime \prime} \mathrm{N}$ & $100^{\circ} 34^{\prime} 11.87505^{\prime \prime} \mathrm{E}$ & 27.351 \\
\hline $\mathrm{CP} 2$ & $5^{\circ} 23^{\prime} 41.85175^{\prime \prime} \mathrm{N}$ & $100^{\circ} 34^{\prime} 12.86529^{\prime} \mathrm{E}$ & 28.019 \\
\hline $\mathrm{CP} 3$ & $5^{\circ} 23^{\prime} 42.90108^{\prime \prime} \mathrm{N}$ & $100^{\circ} 34^{\prime} 11.51145^{\prime} \mathrm{E}$ & 35.297 \\
\hline $\mathrm{CP} 4$ & $5^{\circ} 23^{\prime} 39.95600^{\prime \prime} \mathrm{N}$ & $100^{\circ} 34^{\prime} 12.00562^{\prime} \mathrm{E}$ & 27.446 \\
\hline SGPT & $5^{\circ} 38^{\prime} 36.87953^{\prime \prime} \mathrm{N}$ & $100^{\circ} 29^{\prime} 18.14786^{\prime} \mathrm{E}$ & 10.243 \\
\hline USMP & $5^{\circ} 21^{\prime} 28.03567^{\prime \prime} \mathrm{N}$ & $100^{\circ} 18^{\prime} 14.52961 " \mathrm{E}$ & 19.874 \\
\hline
\end{tabular}

Table 2. The four GPS control points (CP1, CP2, CP3 and CP4)

The data processing phase continue with the processing of total station surveying data by using the intersection method to calculate the three-dimensional local coordinates of each measurement target for the two epochs observations. Table 3 and Table 4 shows the coordinates of the measurement targets for epoch 1 and epoch 2, respectively.

\begin{tabular}{|c|c|c|c|}
\hline targets & $\mathrm{x}$ & $\mathrm{y}$ & $\mathrm{z}$ \\
\hline BW110 & 286924.5702 & 597179.3829 & 29.6043 \\
\hline BW102 & 286891.3776 & 597189.0696 & 40.1953 \\
\hline BW101 & 286895.173 & 597201.7724 & 38.7741 \\
\hline BW119 & 286894.363 & 597209.3939 & 40.0094 \\
\hline BW120 & 286895.9234 & 597218.2137 & 40.0396 \\
\hline BW108 & 286900.5155 & 597208.6855 & 37.0497 \\
\hline BW114 & 286902.0165 & 597216.9459 & 37.1973 \\
\hline BW118 & 286905.8637 & 597225.1285 & 36.2509 \\
\hline BW107 & 286906.8184 & 597190.7643 & 33.2163 \\
\hline BW116 & 286905.9482 & 597198.7633 & 33.629 \\
\hline BW115 & 286903.3702 & 597204.9649 & 35.0426 \\
\hline BW106 & 286918.7694 & 597198.7422 & 30.9916 \\
\hline BW111 & 286910.8803 & 597218.259 & 33.2707 \\
\hline BW104 & 286909.3349 & 597248.5595 & 37.4944 \\
\hline BW103 & 286919.7732 & 597268.8816 & 36.2757 \\
\hline BW105 & 286912.3831 & 597242.8718 & 35.112 \\
\hline & & & \\
\hline
\end{tabular}

\begin{tabular}{|c|c|c|c|}
\hline BW113 & 286914.106 & 597235.8915 & 33.5579 \\
\hline BW117 & 286908.0249 & 597230.8803 & 35.8019 \\
\hline BW112 & 286930.3099 & 597224.8841 & 31.2857 \\
\hline BW109 & 286947.8263 & 597255.4389 & 30.3075 \\
\hline
\end{tabular}

Table 3. 3D coordinates of measurement targets for epoch 1

\begin{tabular}{|c|c|c|c|}
\hline targets & $\mathrm{x}$ & $\mathrm{y}$ & $\mathrm{z}$ \\
\hline BW110 & 286924.6435 & 597179.4663 & 29.6041 \\
\hline BW102 & 286891.4343 & 597189.0802 & 40.1841 \\
\hline BW101 & 286895.2131 & 597201.7698 & 38.7673 \\
\hline BW119 & 286894.393 & 597209.3849 & 40.0061 \\
\hline BW120 & 286895.9479 & 597218.2033 & 40.0389 \\
\hline BW108 & 286900.5329 & 597208.6868 & 37.0464 \\
\hline BW114 & 286902.0177 & 597216.9373 & 37.1966 \\
\hline BW118 & 286905.8763 & 597225.1179 & 36.2515 \\
\hline BW107 & 286906.8522 & 597190.7703 & 33.2167 \\
\hline BW116 & 286905.9803 & 597198.7616 & 33.6266 \\
\hline BW115 & 286903.3912 & 597204.9575 & 35.0405 \\
\hline BW106 & 286918.7878 & 597198.7376 & 30.9962 \\
\hline BW111 & 286910.8992 & 597218.252 & 33.2727 \\
\hline BW104 & 286909.346 & 597248.5434 & 37.4942 \\
\hline BW103 & 286919.7773 & 597268.8658 & 36.2767 \\
\hline BW105 & 286912.395 & 597242.8616 & 35.1118 \\
\hline BW113 & 286914.1159 & 597235.881 & 33.5589 \\
\hline BW117 & 286908.039 & 597230.87 & 35.802 \\
\hline BW112 & 286930.3134 & 597224.868 & 31.2867 \\
\hline BW109 & 286947.8228 & 597255.4349 & 30.3083 \\
\hline BW & \\
\hline
\end{tabular}

Table 4. 3D coordinates of measurement targets for epoch 2

The final stage of data processing involves with the processing of the two epochs mobile laser scanning data. The processing tasks involves with the cleaning, filtering and merging of threedimensional point cloud data using GIS spatial analysis methods. Figure 10 shows the overall scanning data of the study area. The coordinate system applied to the data is World Geodetic System (WGS) 84

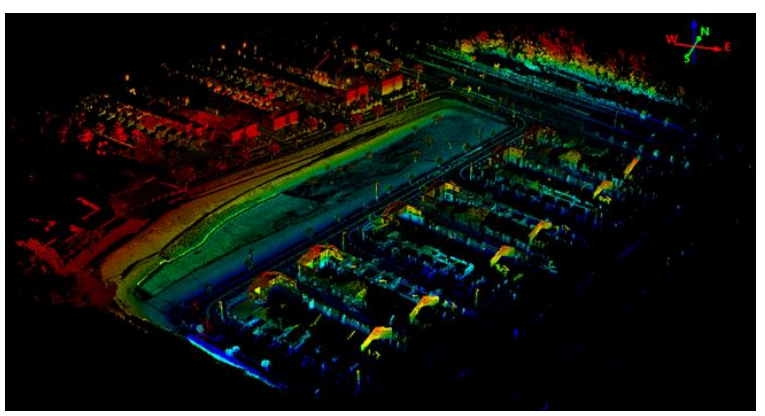

Figure 10. The overall scanning data of the study area 
The cleaning process was then applied to the overall scanning data. The purpose of the cleaning process is to delete the unused point cloud data that belong to the man-made objects such as houses, trees and others. The cleaning data was carried out manually. Figure 11 shows the point cloud data that has been cleaned from the overall scanning data.

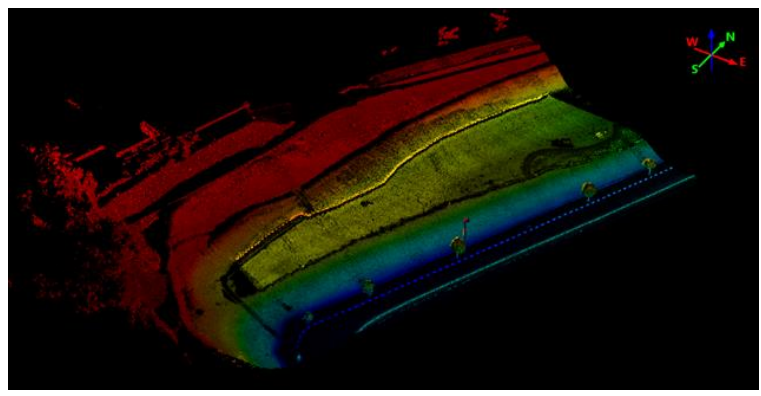

Figure 11. Mobile laser scanning data after cleaning process

The point cloud data (as shown in Figure 11) was then filtered using Adaptive TIN method. The purpose of the filtering method is to separate the ground point cloud data from the nonground data. The final output is the ground point cloud data of the study area. The filtering process was carried out using TerraScan software. The Adaptive TIN filtering method requires special parameters to perform the filtering process. Table 5 shows the parameters and the selected values that have been used in filtering the point cloud data.

\begin{tabular}{|c|c|}
\hline Parameter & Value \\
\hline Max. building size & $40.0 \mathrm{~m}$ \\
\hline Terrain angle & $50^{\circ}$ \\
\hline Iteration angle & $3.5^{\circ}$ to plane \\
\hline Iteration distance & $0.5 \mathrm{~m}$ to plane \\
\hline Reduce iteration angle when & $1.0 \mathrm{~m}$ \\
\hline
\end{tabular}

Table 5. Selected parameters for the filtering process using Adaptive TIN method

The selection and determination of values for each parameter are referring to the actual situation of the study area. The results of the filtering process are shown in Figure 12.

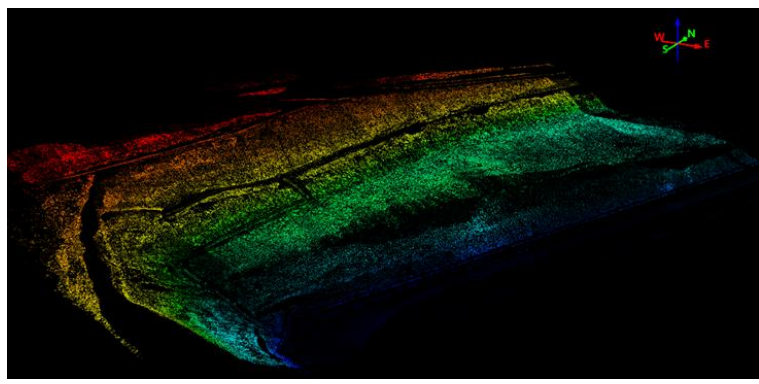

Figure 12. Filtered mobile laser scanning data

The final step in the processing of mobile laser scanning data is a merging process. The purpose of the merging process is to accurately merge the three sets of point cloud data that has been acquired and filtered. The merging process was carried out using a merging algorithm that was provided in the geoprocessing tools embedded in ArcGIS software. Figure 13 shows the mobile laser scanning data before merging process. While Figure 14 shows the final result of the merging process.

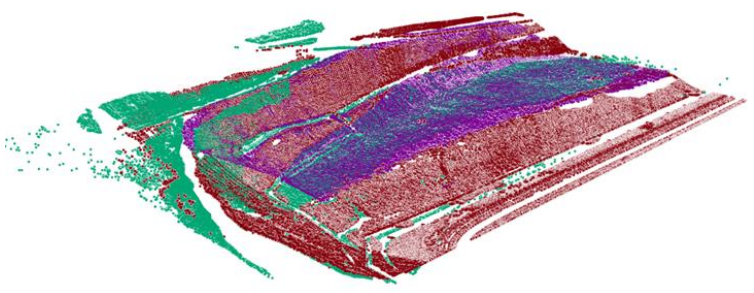

Figure 13. Mobile laser scanning data before merging process

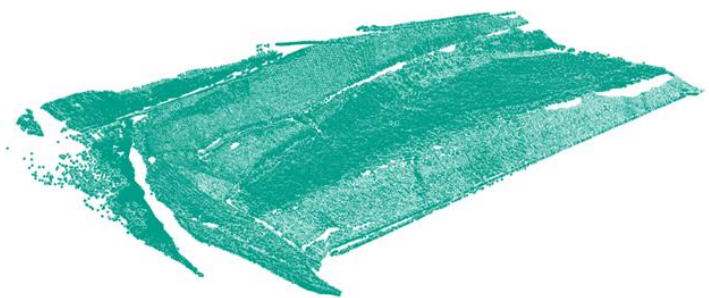

Figure 14. Result for the merging process

Table 6 summarized the chronology of the mobile laser scanning data processing tasks in the aspect of the density of 3D points. The two epoch's mobile laser scanning data was processed separately.

\begin{tabular}{|c|c|c|}
\hline Chronology & Epoch 1 & Epoch 2 \\
\hline All points (RAW data) & 151314709 & 179634130 \\
\hline After Crop & 99286106 & 116976329 \\
\hline After Filter & 382029 & 390197 \\
\hline After Merge & 325185 & 357745 \\
\hline
\end{tabular}

Table 6 . The chronology of the mobile laser scanning data processing tasks

Table 6 shows that the density of the point cloud data started to largely reduced when the data was filtered. The situation is happening caused by the removal of non-ground points from the original dataset. As clearly shown in Table 6 that the merging process was also reduce the density of the filtered data caused by the removal of the redundant points in each dataset. The final mobile laser scanning data is the 3D point clouds data that only belong to the terrain features of the study area.

\subsection{Phase 4 - Data Analysis}

The data analysis phase begins with the analysis of the two epochs total station survey data to detect movement of the landslide. The movement analysis will be based on the differences between the 3D coordinates of the measurement targets. Table 7 shows the differences of the 3D coordinates for the measurement targets. 


\begin{tabular}{|c|c|c|c|}
\hline Targets & X (easting) & Y (northing) & Z (height) \\
\hline BW110 & 0.0733 & 0.0834 & -0.0002 \\
\hline BW102 & 0.0567 & 0.0106 & -0.0112 \\
\hline BW101 & 0.0401 & -0.0026 & -0.0068 \\
\hline BW119 & 0.03 & -0.009 & -0.0033 \\
\hline BW120 & 0.0245 & -0.0104 & -0.0007 \\
\hline BW108 & 0.0174 & 0.0013 & -0.0033 \\
\hline BW114 & 0.0012 & -0.0086 & -0.0007 \\
\hline BW118 & 0.0126 & -0.0106 & 0.0006 \\
\hline BW107 & 0.0338 & 0.006 & 0.0004 \\
\hline BW116 & 0.0321 & -0.0017 & -0.0024 \\
\hline BW115 & 0.021 & -0.0074 & -0.0021 \\
\hline BW106 & 0.0184 & -0.0046 & 0.0046 \\
\hline BW111 & 0.0189 & -0.007 & 0.002 \\
\hline BW104 & 0.0111 & -0.0161 & -0.0002 \\
\hline BW103 & 0.0041 & -0.0158 & 0.001 \\
\hline BW105 & 0.0119 & -0.0102 & -0.0002 \\
\hline BW113 & 0.0099 & -0.0105 & 0.001 \\
\hline BW117 & 0.0141 & -0.0103 & 0.0001 \\
\hline BW112 & 0.0035 & -0.0161 & 0.001 \\
\hline BW109 & -0.0035 & -0.004 & 0.0008 \\
\hline
\end{tabular}

Table 7. The differences of 3D coordinates of the measurement targets between epoch 1 and epoch 2 observations

The statistical analysis was then used to plot the differences of the 3D coordinates of the measurement targets have been showed in Table XX. The data analysis phase was end up with the surface deviation analysis process between the two epochs of MLS data that was carried out to detect the movement of the landslide area.

\section{RESULTS AND ANALYSIS}

As mentioned elsewhere in the beginning of the paper, the results of the study were divided in two parts which are:

a) The results from the total station survey showing the movement of the landslide area by single-point-based analysis, and

b) The results from the mobile laser scanning survey showing the movement of the landslide area by surface-based analysis

\subsection{Results from Total Station Survey}

The results from the total station survey were based on the analysis of each measurement targets that was setup at the study area. The spider web graph was used to plot the movement of each measurement targets. Figure 15 shows the overall movements of all the twenty measurement targets.

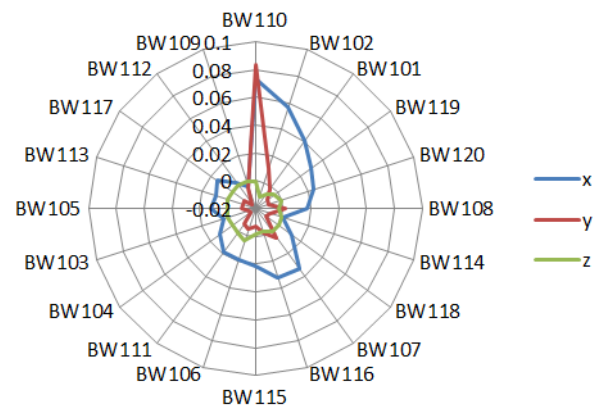

Figure 15. Overall movement analysis of the measurement targets
Figure 15 shows that all measurement targets are exposed to the movement within 30 days period. All measurement targets are moving in all directions. Results also show that there are significant movements in $\mathrm{x}$ and $\mathrm{y}$ directions. While small movements are detected in the $\mathrm{z}$ direction.

Figure 16, Figure 17 and Figure 18 shows the plot of the movement analysis which refer to easting (x) and northing (y) coordinates, and the height $(\mathrm{z})$, respectively.

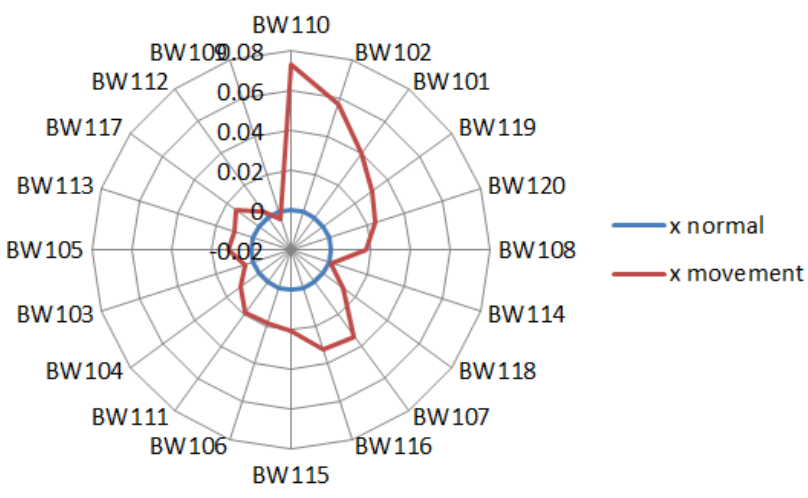

Figure 16. The movement analysis of the measurement targets based on the differences of easting coordinates (x normal indicates that there is no movement in the study area)

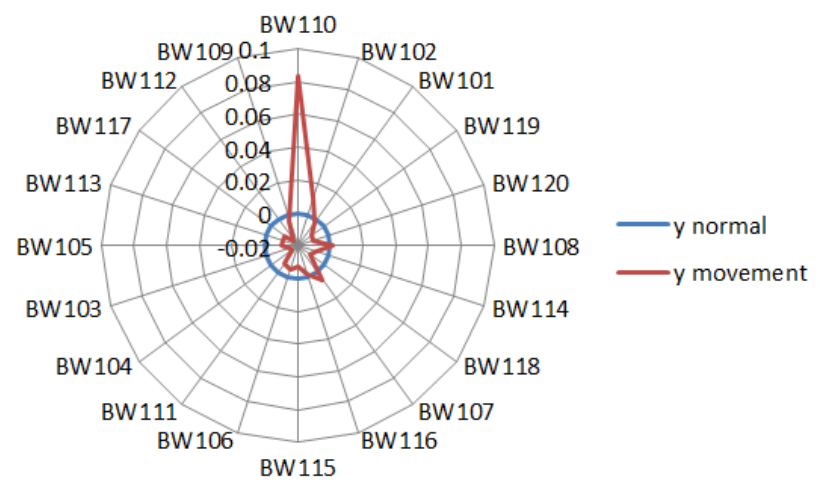

Figure 17. The movement analysis of the measurement targets based on the differences of northing coordinates (y normal indicates that there is no movement in the study area)

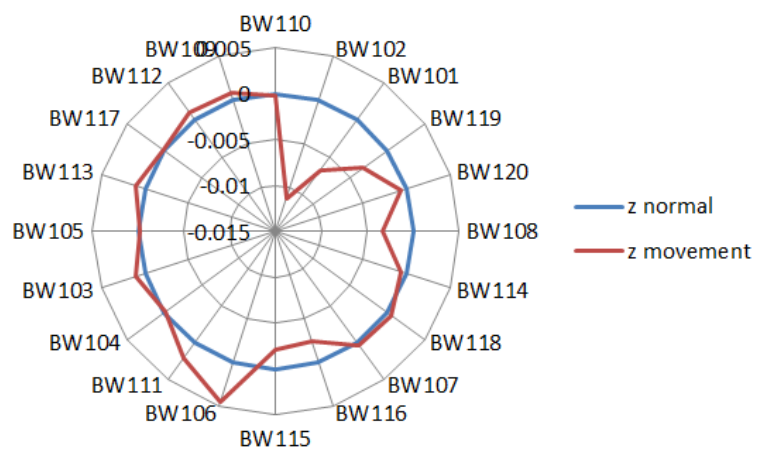

Figure 18. The movement analysis of the measurement targets based on the differences of height ( $\mathrm{z}$ normal indicates that there is no movement in the study area) 
Based on the results obtained, a preliminary decision can be made that there is a ground movement in the study area. However the total station measurement method is limited to the movement of the ground which refers to the point being measured and not referring to the surface movement.

\subsection{Results from Mobile Laser Scanning Survey}

The analysis of the mobile laser scanning data was carried out using Cloud Compare software. The analysis involved with the surface deviation analysis of the filtered point clouds dataset between the two epochs. Two registration methods were used to integrate the two epochs point cloud data which are the Iterative Closest Point (ICP) and Align Point Pairs Picking methods. The outcomes from surface deviation analysis are compared to the actual situation in the study area where the soil crack occurs. Figure 19 shows the location of the soil crack at the study area.

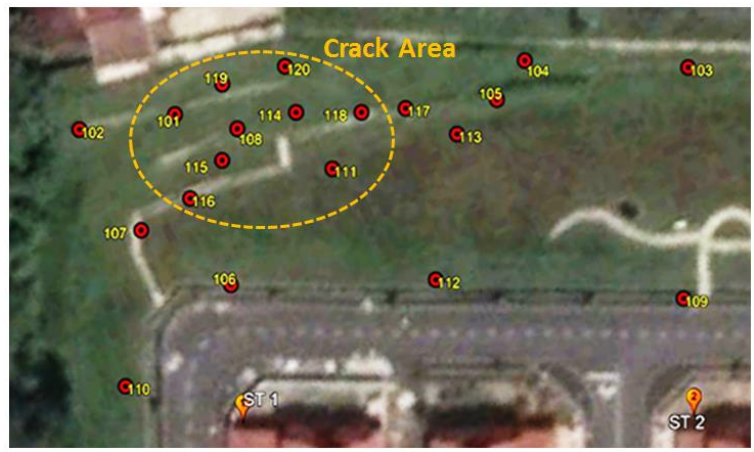

Figure 19. The location of the crack at the study area

The Iterative Closest Point (ICP) registration method was carried out automatically. The Cloud Compare software allows the user to define the reference and the aligned point cloud data. Few parameters involved in the ICP method which are number of iteration, the RMS difference and random sampling unit. Figure 20 shows the ICP registration method offers by the Cloud Compare software.

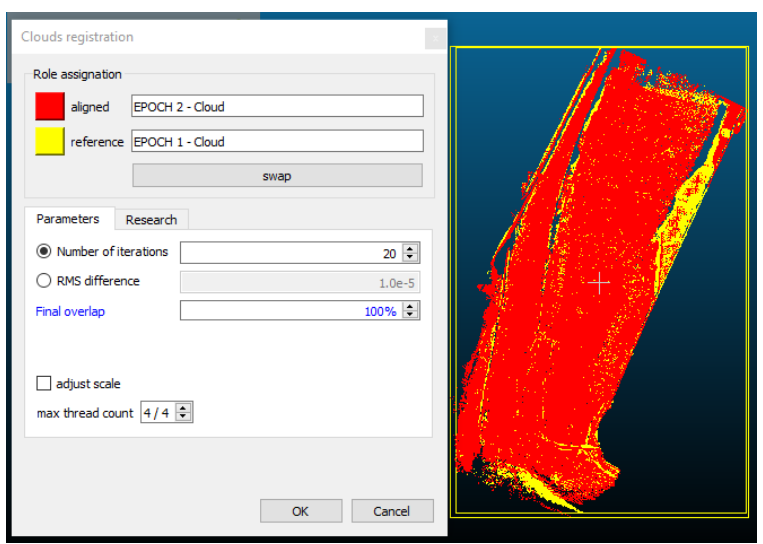

Figure 20. The registration process using Iterative Closest Point (ICP) method

The accuracy of the registration process using ICP method was determined from the root mean square (RMS) value that was calculated automatically in the software. The transformation matrix was also generated to help the researcher to analyze the effectiveness of the ICP method. Figure 21 shows the results from the ICP method.

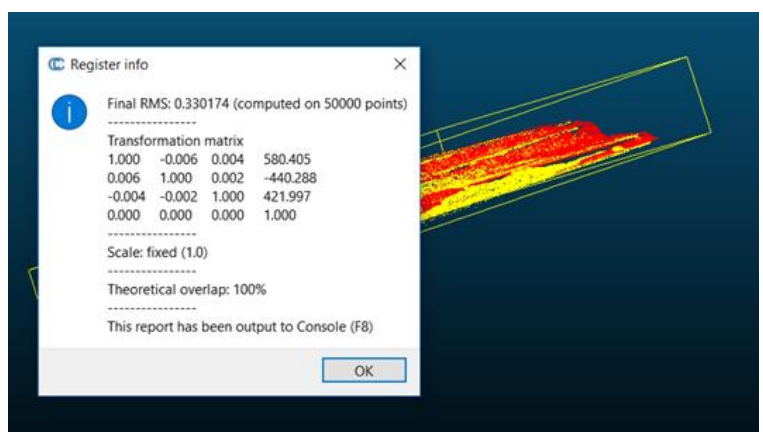

Figure 21. The result from the registration process using Iterative Closest Point (ICP) method

The Cloud to Clouds Distance method was then used to calculate the deviation between the point clouds dataset. Cloud Compare software allows the user to define the compared and reference data to be used for the computation of the distance between the two point clouds datasets. Users can define the value of the maximum distance to be used in the computation. Figure 22 shows the Cloud to Cloud distance computation menu in the Cloud Compare software. While Figure 23 shows the surface deviation analysis result that was calculated from the ICP registration output.

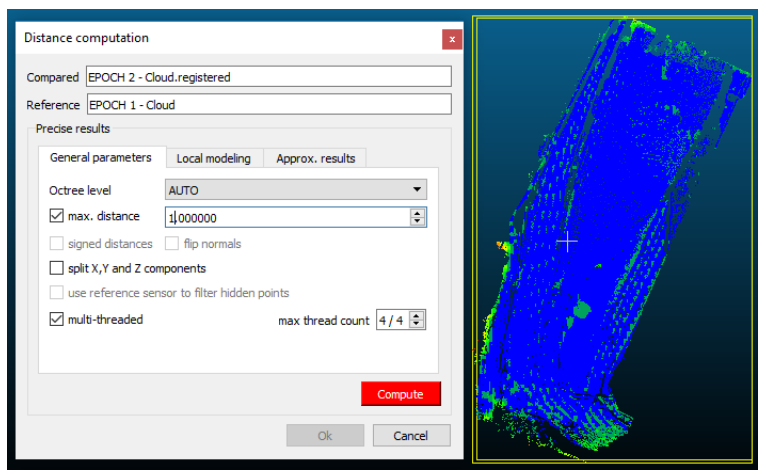

Figure 22. The Cloud to Cloud distance computation process in Cloud Compare Software

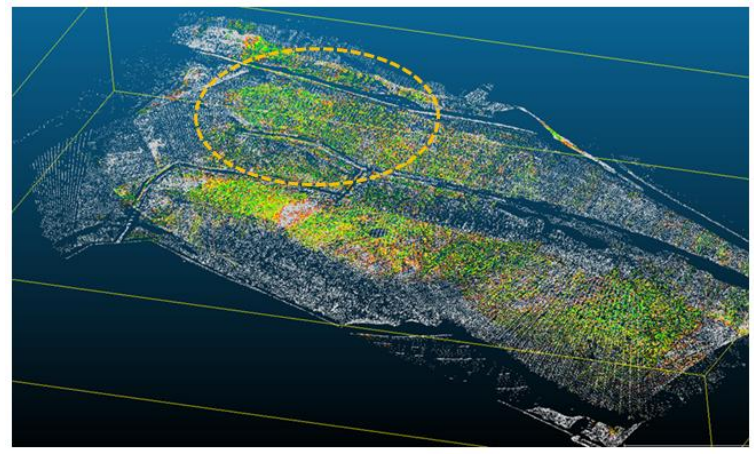

Figure 23. The surface deviation analysis with the output from the Iterative Closest Point (ICP) method

From Figure 23, it can be seen that mobile laser scanner data can be used to map the changes between two epoch observations. The area marked with a dotted line indicates the 
occurrence of land movements. This situation is true as compared to the actual situation as shown in Figure 19.

Figure 24 shows the registration process using the Align Point Pairs Picking method. In this method, five corresponding points was identified and digitized on both epoch 1 and epoch 2 filtered mobile laser scanning point clouds. The corresponding point was marked manually. The 3D coordinates of each point was recorded in the given table.

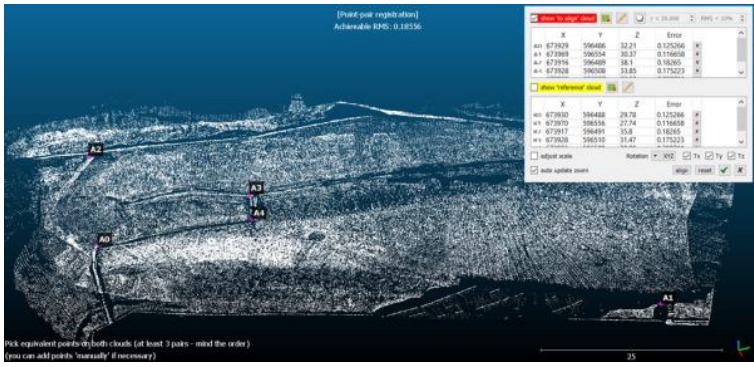

Figure 24. The registration process using Align Point Pairs Picking method

The accuracy of each digitized points was determine from the recorded error value of the point. The points with bigger errors were deleted from list. The overall accuracy of the alignment process was determined from the calculated root mean square (RMS) value. Figure 25 shows the results from the registration process using Align Point Pairs Picking method.

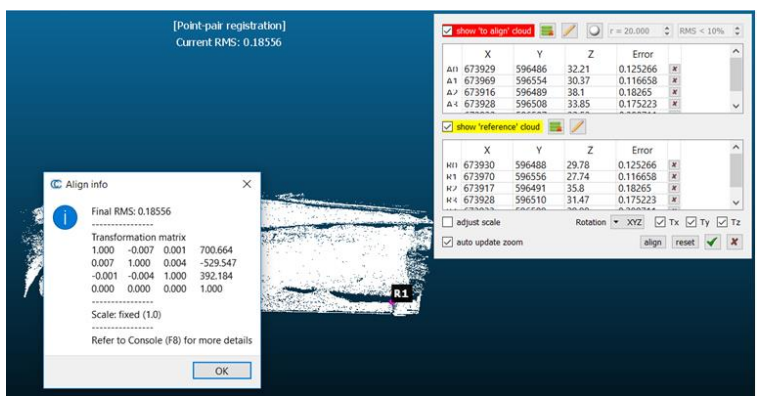

Figure 25. The result from the registration process using Align Point Pairs Picking method

Figure 26 shows the surface deviation analysis result as an output from the Align Point Pairs Picking registration method. The area marked with the dotted line indicates the occurrence of land movements. Again, this situation is true as compared to the actual situation as shown in Figure 19.

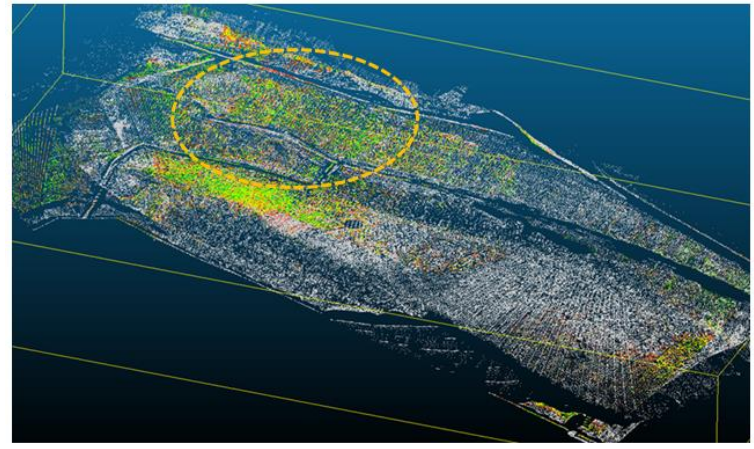

Figure 26. The surface deviation analysis with the output from the Align Point Pairs Picking registration method

\section{CONCLUSION}

In general, this paper describes two methods that can be used to detect land movements in areas threatened by landslide phenomena. Both methods are based on the Geoinformation technology. The first method is the total station measurement method which is based on a single point measurement approach The second method is the mobile laser scanning measurement method which is based on surface measurement approach.

In this study, the total station measurement method was used to track the movement based on the changes of the value of threedimensional coordinate for twenty measurement targets setup at the study area. With two epoch-based measurements, the movement of twenty measurement targets was successfully detected with survey grade accuracy. This result is used as a reference to the mobile laser scanning measurement method in detecting land movements in the same area.

The movement detection process of the landslide area using mobile laser scanning method involves the process of comparing the changes in point cloud data that was acquired in two epoch's basis. Two registration methods are used to register the two epoch's data which are ICP method and Align Point Pairs Picking method. The cloud to cloud method is used to measure the optimum distance between the two point cloud data to detect any changes to the data. The research shows that both methods can be used to detect land movements in the study area.

It can be concluded that the purpose of the study (ie to evaluate the ability of mobile laser scanning methods to monitor landslides) is achieved. Mobile laser scanning method has several advantages over other methods:

a) data collection of landslide can be completed quickly and effectively;

b) the method is able to produce high density data that can be used to map the areas affected by land movement, and

c) the process of mapping the ground movements can be done on a surface basis where this method can illustrate the impact of the movement more meaningfully as compared to the point-based measurement method

\section{ACKNOWLEDGEMENT}

The author thanked UTM for awarding the GUP Tier 1 research fund (Vot 19H69). The authors would also like to thank the Geospatial Imaging \& Information Research Group and the Faculty of Geoinformation \& Real Estate UTM. 


\section{REFERENCES}

Babić L, Pribičević B and Đapo A, 2012. Mobile Laser Scanning (MLS) in transport infrastructure documentation and research. Ekscentar (15), 96-99.

Kukko, A, 2013. Mobile Laser Scanning-System development, performance and applications: Finnish Geodetic Institute

Michoud C, Carrea D, Costa S, Derron M.H, Jaboyedoff M, Delacourt C, Maquaire O, Letortu P and Davidson R, 2015. Landslide detection and monitoring capability of boat-based mobile laser scanning along Dieppe coastal cliffs, Normandy, Landslide, Volume 12,Issue2,pp 403-418

Qin R and Gruen A, 2014. 3D change detection at street level using mobile laser scanning point clouds and terrestrial images, International Society for Photogrammetry and Remote Sensing, Volume 90, April 2014, Pages 23-35

Vaaja M, Hyyppä J, Kukko A, Kaartinen H, Hyyppä H and Alho P, 2011. Mapping Topography Changes and Elevation Accuracies Using a Mobile Laser Scanner, Remote Sens. 2011, 3(3), 587-600

Wang H, Cai Z, Luo H and Li J, 2012. Automatic road extraction from mobile laser scanning data, Computer Vision in Remote Sensing (CVRS), DOI 10.1109 /CVRS. 2012. 6421248

Xio W, Vallet B, Bredif M and Paparoditis N, 2015. Street environment change detection from mobile laser scanning point clouds, International Society for Photogrammetry and Remote Sensing, Volume 107, September 2015, Pages 38-49 